\title{
A INFLUÊNCIA DA FLORESTA CILIAR SOBRE A TEMPERATURA DAS ÁGUAS DO RIO CAPIVARI, REGIÃO CÁRSTICA CURITIBANA
}

\author{
Elenice Fritzsons*, Luiz Eduardo Mantovani**, Anselmo Chaves Neto***, Nivaldo Eduardo Rizzi**** \\ *Eng. Agrônoma, Dr ${ }^{\mathrm{a}}$. - elenfrt@brturbo.com.br. \\ **Geólogo, Dr., Depto. de Geologia da UFPR - lem@ufpr.br \\ ***Matemático, Eng. Civil, Dr., Depto. de Estatística da UFPR - anselmo@est.ufpr.br \\ ****Eng. Florestal, Dr., Depto. de Engenharia e Tecnologia Florestal da UFPR - niva@floresta.com.br \\ Recebido para publicação: 12/04/2004 - Aceito para publicação: 14/10/2005
}

\begin{abstract}
Resumo
A influência da floresta ciliar sobre a temperatura das águas do rio Capivari, região cárstica curitibana. As florestas ciliares são essenciais para proteger a qualidade das águas dos rios e, pelo efeito de sombreamento, interceptam e absorvem a radiação solar, contribuindo para a estabilidade térmica, evitando excessivos aquecimentos diurnos e resfriamentos noturnos. Nessa concepção, o presente trabalho objetiva avaliar o equilíbrio térmico das águas do rio Capivari, região do Carste Curitibano, durante um intervalo médio de 12 anos. Foi definido e aplicado o índice "amplitude térmica relativa" para os anos de 1986/87 e os de 1998 a 2000, utilizando-se os dados diários da temperatura do ar e da água. Os resultados revelaram que as águas do rio Capivari se mostraram significativamente mais "tamponadas" termicamente de 1998 a 2000 em relação aos anos de 86/87. Estudos envolvendo mapeamento e quantificação das florestas ciliares na bacia de estudo revelaram um acréscimo das florestas em 1996 em relação a 1980, evidenciando que esta poderia ser a causa do maior equilíbrio térmico encontrado nas águas fluviais.
\end{abstract}

Palavras-chave: Temperatura e floresta ciliar; amplitude térmica fluvial; ecologia de paisagem; floresta ciliar.

\begin{abstract}
The consequences of riparian forest change over fluvial temperature, Capivari stream, curitibana cárstic region, Brazil. Riparian forests are essential for protecting river waters and the shading effect, they intercept and absorb the solar radiation contributing to the thermal stability, preventing the extremes: diurnal heating and the nocturnal cooling. Following this conception, this paper leads to evaluate the fluvial water temperature alteration in Capivari stream, Paraná subtropical carstic region, during an average interval of 12 years. Thus, the index thermic range was developed and applied from 1986 to 1987 and from 1998 to 2000. Daily data of the temperature of air and water were used. The data analysis shows that the stream water significantly more thermal balanced from 1998 to 2000 than in 1986/87. Studies involving mapping and quantification of the riparian forests in the study basin reveal an addition of the forests in 1996 than 1980. Thus gives support that this increase in forests numbers could be the cause of the higher thermal balance equilibrium found in fluvial waters.

Keywords: Temperature and riparian forest; fluvial thermic range; landscape ecology; riparian forest.
\end{abstract}

\section{INTRODUÇÃO}

A temperatura constitui um fator limitante à existência e ao desenvolvimento de muitas espécies, pois, embora haja uma variação de milhares ou mesmo milhões de graus existentes no Universo, sabe-se que a vida, conforme é conhecida, pode existir apenas numa pequena faixa de aproximadamente $-200{ }^{\circ} \mathrm{C}$ a $+100{ }^{\circ} \mathrm{C}$, sendo que a maioria das espécies está restrita a uma faixa ainda menor (Odum, 1983).

Os ecossistemas aquáticos estão adaptados a variações de temperatura da água relativamente limitadas, devido ao alto valor do calor específico e às mudanças de estado físico da água, que absorvem ou liberam calor latente.

A elevação da temperatura das águas também pode provocar um aumento na ação tóxica de muitos elementos e compostos químicos, sendo freqüente a maior mortandade de peixes, durante o verão, 
em águas poluídas. Além disso, segundo Mota (1995), um aumento de temperatura também diminui a viscosidade da água, provocando a submersão de muitos microorganismos.

O lançamento de efluentes industriais aquecidos, tais como água de refrigeração de caldeiras e turbinas, provoca poluição térmica nos rios, podendo afetar diretamente a flora e a fauna aquáticas e, devido à diminuição da concentração de OD (oxigênio dissolvido), agravar o problema de poluição (Branco e Rocha, 1977). Mesmo assim, não há limites numéricos, de acordo com as normas do CONAMA (n 20/86) ou Portarias do Ministério da Saúde, quanto à temperatura para as águas brutas. Entretanto, SUDERHSA (1997) observa que deve ser evitada qualquer modificação na temperatura que prejudique a operação da estação de tratamento, como, por exemplo, que acelere as reações químicas, altere o regime hidráulico dos decantadores, as necessidades de filtração etc.

A temperatura média anual de rios de locais temperados e tropicais se situa entre zero e $25{ }^{\circ} \mathrm{C}$, mas em desertos pode chegar a $40^{\circ} \mathrm{C}$, próxima da tolerância termal das espécies estenotérmicas (Allan, 1995).

Considerando que a vazão de estiagem dos rios em grande parte é formada pela contribuição das águas subterrâneas, estas muito contribuem para a temperatura dos rios. Segundo Allan (1995), as águas subterrâneas estão a maior parte do tempo em torno de $1{ }^{\circ} \mathrm{C}$ acima da média anual da temperatura do ar, e em corpos d'água em que a contribuição da entrada de água subterrânea é importante, como em fontes e em alguns rios de cabeceira, a variação da diferença sazonal pode ser insignificante. Isso é verdadeiro para águas subterrâneas mais superficiais, pois as mais profundas se aquecem segundo os gradientes termais positivos do interior da terra.

Para as águas correntes, a variação da temperatura se deve às estações do ano, hora do dia, altitude, extensão da vegetação ripária e à importância relativa da entrada de água subterrânea. UNESCO (1974) ainda considera importantes as circulações do ar, a cobertura de nuvens, o fluxo e a profundidade do corpo de água.

Quanto às florestas ripárias, são ambientes únicos devido à sua posição na paisagem. Constituem ecótones entre zonas aquáticas e terrestres e mesmo corredores que conectam regiões e funcionam, em termos micrometeorológicos, como um "oásis", absorvendo energia, evaporando a água, aumentando a umidade do local e diminuindo sua temperatura. Formam, assim, um ecossistema diferenciado das bordas. A figura 1 exemplifica esse efeito durante o dia. Entretanto, durante a noite, a curva da temperatura tende a se inverter.

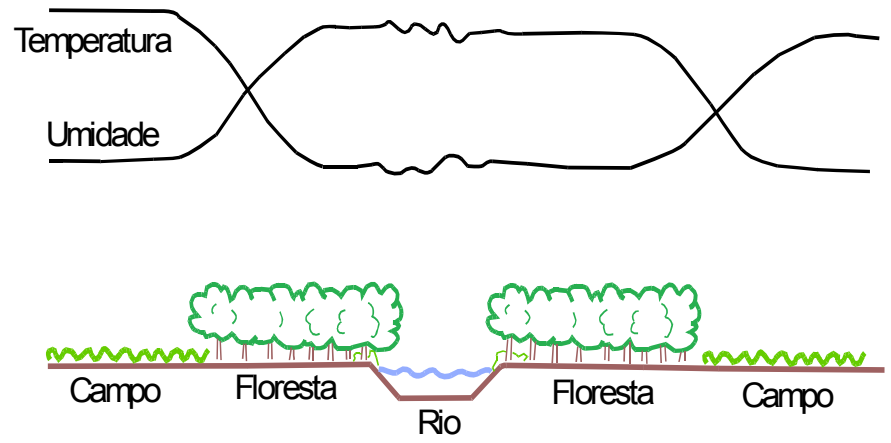

Figura 1. Esquema do "efeito oásis" da zona ripária.

Figure 1. Oasis effect by riparian zone.

Fonte: Malanson (1993).

Além disso, nos fundos dos vales a presença de neblina é comum, devido à condensação de vapores de água, principalmente durante a madrugada, persistindo, às vezes, nas primeiras horas do dia. Isso ocorre pela manutenção de temperatura da água superior à do ar durante a noite, facilitando a evaporação por aceleração da atividade convectiva sobre os espelhos d'água, e posterior condensação do vapor em contacto com o ar noturno ou com a vegetação, que se encontram mais frios, provendo as florestas ribeirinhas de uma maior umidade. O orvalho depositado sobre folhas e ramos tanto goteja até o solo quanto volta a evaporar. Assim, as florestas ciliares, situadas nos fundos dos vales, colaboram 
fortemente para uma maior freqüência de névoas e neblinas, sob inversão térmica noturna, contribuindo com mais esse fator convergente para a estabilidade térmica dos rios sob floresta ciliar (Mantovani, 1996).

O autor supracitado afirma ainda que a névoa e a neblina formadas a partir da condensação de gotas decimilimétricas de água atuam também como forte agente refletivo na faixa do infravermelho termal (faixa entre 6 e 20 micrômetros), reduzindo drasticamente a irradiação noturna. Esse processo ocorre, sobretudo em noites de circulação mais calma (velocidade do vento próximo à superfície menor do que $2 \mathrm{~m} / \mathrm{s}$ ), resultando na condensação de orvalho sobre o solo e vegetação, além de formação de névoas no ar, num processo que libera calor latente de condensação para o ambiente $\left(539 \mathrm{cal}^{\mathrm{g}} \mathrm{g}^{-1}\right.$ ou 2,26

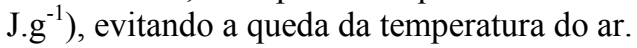

A integração da zona ripária com a superfície da água proporciona cobertura e alimentação para peixes e outros componentes da fauna aquática e, pelo efeito de sombreamento, intercepta e absorve a radiação solar, o que também contribui para a estabilidade térmica (Lima, 1989). A vegetação ripária, pelo efeito de interceptação, também dificulta a perda de calor da água por irradiação noturna, como exemplifica a figura 2 .

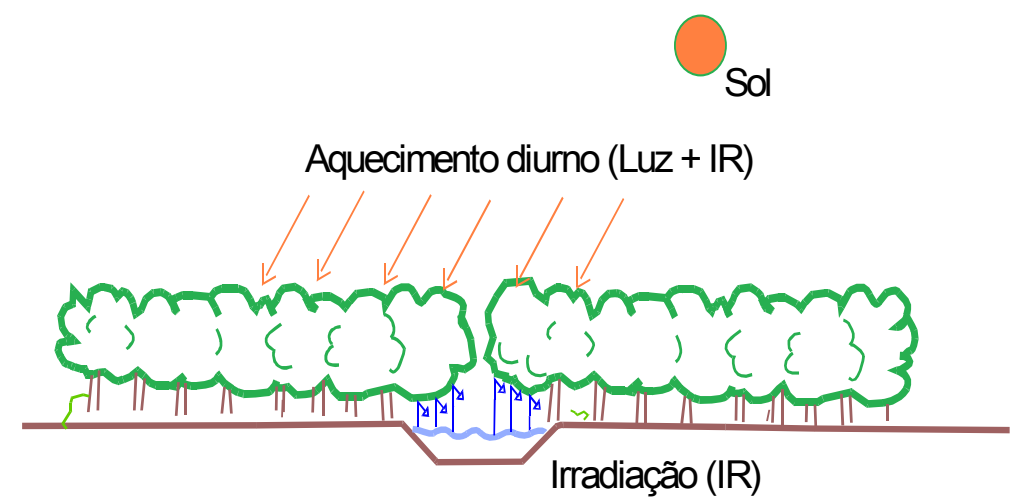

Figura 2. Influência da floresta ciliar na irradiação solar e perda por irradiação noturna em rios.

Figure 2. Riparian forest protection against direct solar irradiation and loss by noturn irradiation.

Fonte: Fritzsons, 2003.

De acordo com Vannote e Sweeney (1980) citados por Allan (1995), esse efeito é mais importante em rios pequenos ou de cabeceiras (stream brooks), pois, devido à influência da entrada das águas subterrâneas e do sombreamento, freqüentemente são menos variáveis termicamente. A temperatura das águas dos grandes rios não é comumente afetada por sombreamento, pois, devido ao seu grande volume, eles possuem considerável inércia termal. Assim, a variação da temperatura é maior em rios de tamanho intermediário, como ilustra a figura 3, a qual relaciona o tamanho do rio ao número de ordens e à máxima variação da temperatura em graus Celsius.

Nakamura e Dokai (1989) observaram que a temperatura das águas do rio Honorai, no Japão, depois de passarem por uma área de proteção das florestas ciliares, se elevava, devido à exposição direta aos raios do sol. No verão, o aumento diário máximo chegava a $4{ }^{\circ} \mathrm{C}$. Os autores também observaram que o efeito dessa cobertura decrescia com a largura do rio. Assim, rios maiores estariam menos sujeitos às variações térmicas, como mostrado na figura 3.

A retirada da floresta ciliar traz inúmeras implicações ecológicas e microclimáticas. Nagasaka e Nakamura (1999) estudaram as mudanças no sistema hidrológico e no ecossistema ripário quanto à alteração no uso da terra, numa bacia no Japão. Eles verificaram que a temperatura da água no verão aumentou, em média, de $22{ }^{\circ} \mathrm{C}$ em 1947, para $28{ }^{\circ} \mathrm{C} 42$ anos depois, o que gerou uma série de interferências na biota (por exemplo, o desaparecimento de certas espécies de peixes, como os salmonídeos).

Arcova e Cicco (1998), em trabalho realizado em Cunha, na bacia do rio Paraíba do Sul, no estado de São Paulo, monitoraram a qualidade de água em 7 microbacias com diferentes usos de solo, que 
incluíam: floresta natural, pastagem, agricultura e floresta natural associada ao reflorestamento, em diferentes combinações. Como resultado parcial, concluíram que nas microbacias onde foram retiradas as florestas (matas) ciliares, houve elevação da temperatura da água.

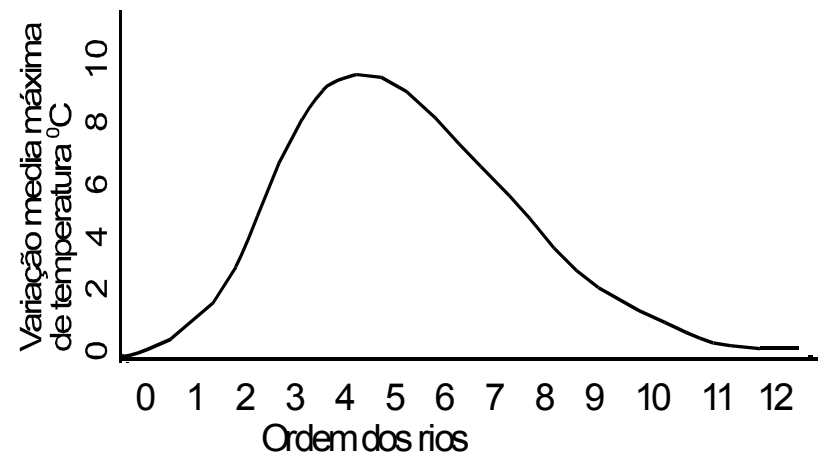

Figura 3. Variação máxima média da temperatura diária da água (em oc) em relação às ordens dos rios de clima temperados.

Figure 3. Maximum daily temperature range in relation to stream order in rivers of temperature climate. Fonte: Vannote e Sweeney (1980) ${ }^{1}$, citados por Allan (1995).

Tendo em vista a importância da floresta ciliar na manutenção da temperatura fluvial, e partindo da hipótese de que águas com temperaturas mais equilibradas poderiam estar relacionadas a bacias com maior proteção da vegetação ciliar, este trabalho tem por objetivo observar a influência da floresta ciliar na alteração da temperatura das águas do rio Capivari.

Para isso, foi desenvolvido um método em que se avaliou a alteração da temperatura fluvial por meio de um índice denominado de "amplitude térmica ar/água". Esse índice foi aplicado tratando-se dados diários, numa perspectiva temporal, em duas épocas: 1986/87 e 1998 a 2000. Para tratamento estatístico, foi utilizada a ANOVA, do programa estatístico Statigraphics. Paralelamente, foram observadas, em fotos aéreas, as alterações nas florestas ciliares, de forma quantificada e temporal, para toda a bacia.

\section{MATERIAL E MÉTODOS}

\section{Descrição da área de trabalho}

O estudo foi desenvolvido na bacia hidrográfica do Alto Capivari, localizada ao norte da região urbana de Curitiba, pertencente à bacia do Ribeira do Iguape, agrupada no denominado conjunto hidrográfico do Atlântico Leste. O clima subtropical de altitude se caracteriza como Cfb, baseado na classificação de Köeppen, com pluviometria média de $1400 \mathrm{~mm}$ e evapotranspiração em torno de 800 mm, não apresentando, em média, estação seca (Maack, 1981).

Essa região pertence à faixa do denominado Carste do Primeiro Planalto Paranaense, englobando terrenos da Formação Capiru do Grupo Açungui e, mais a norte, do Grupo Setuva. A Formação Capiru apresenta como característica marcante rochas metadolomíticas, em grande parte de sua área, dispostas em faixas alongadas, acompanhadas de filitos, quartzitos e o conjunto sendo cortado por diques de doleritos ou diabásios, geralmente impermeáveis aos fluxos freáticos.

Trata-se de uma bacia de formato bastante irregular, com $125,19 \mathrm{~km}^{2}$ (12.519 ha) e um perímetro de $82,5 \mathrm{~km}$. A bacia apresenta em seu exutório a ETA (Estação de Tratamento de Água da SANEPAR) de São Dimas, onde o rio Capivari apresenta sua largura máxima de 9 metros, sendo a vazão média do rio (tomada nos anos de 1997, 1998 e 1999 e próximo a esse ponto) de 3,5 $\mathrm{m}^{3} \cdot \mathrm{s}^{-1}$, com fortes alterações nos períodos de precipitação e estiagem, de acordo com os dados da SUDERHSA (2000).

\footnotetext{
${ }^{1}$ VANNOTE, R. L. e SWEENEY, B.W. Geographical analyses of thermal equilibria. Am. Nat. 115, 667-95.
} 
A bacia passa para $6^{\mathrm{a}}$ ordem nas proximidades do exutório e pode ser dividida em duas grandes sub-bacias, correspondentes aos dois maiores rios que compõem a rede de drenagem, o rio Bacaetava e o Rio Capivari. O rio Bacaetava é um afluente do rio Capivari, e a sub-bacia do Bacaetava ocupa a porção oeste da área estudada; já a sub-bacia do Capivari ocupa a porção norte/leste e compreende as nascentes do rio Capivari. A figura 4 ilustra a drenagem da bacia e os dois rios maiores da bacia de estudo.

\section{Bacia hidrográfica do Alto Capivari}

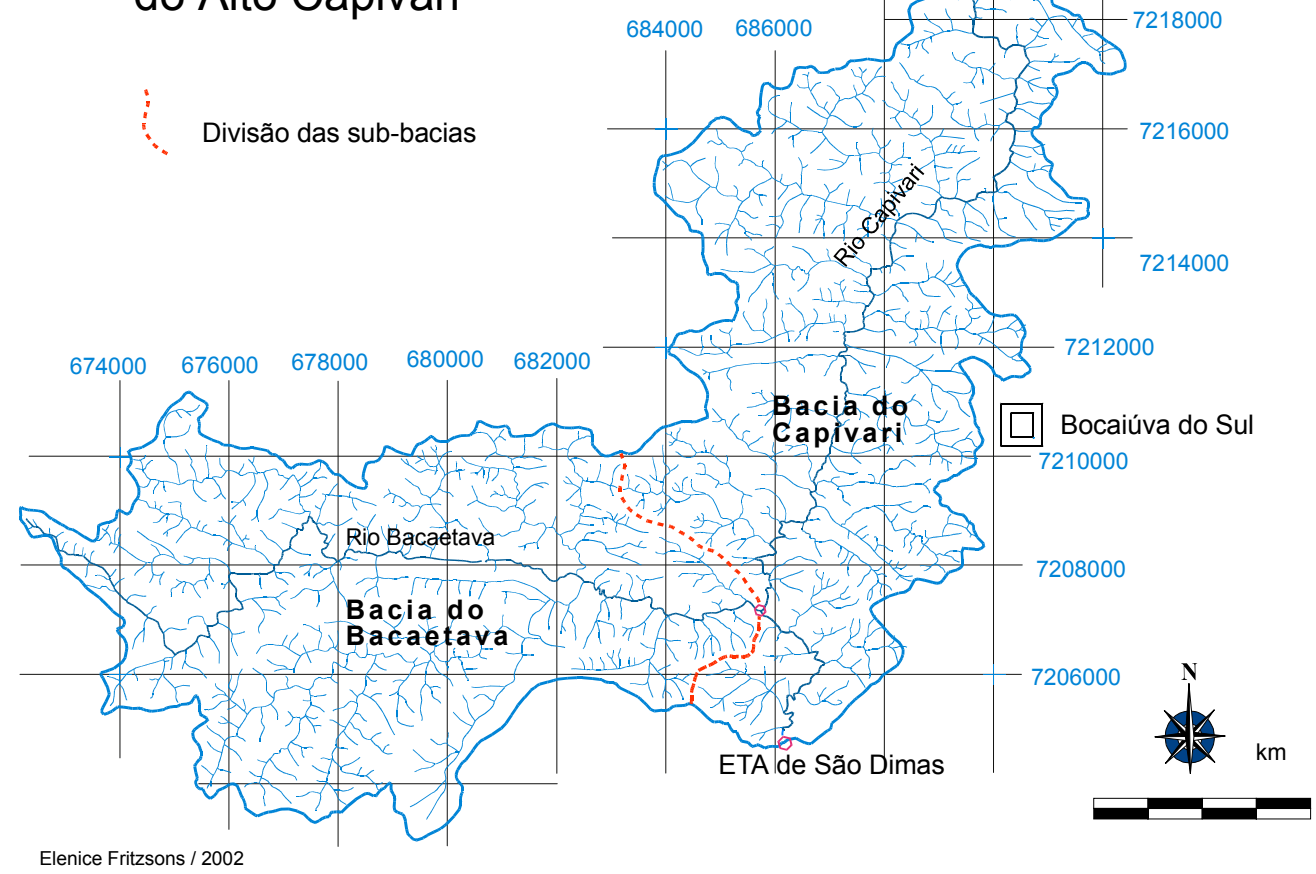

Figura 4. Bacia hidrográfica do Alto Capivari.

Figure 4. Alto Capivari hidrographic basin.

Fonte: Fritzsons, 2003.

Assim, o rio Capivari recebe o rio Bacaetava e, deixando a bacia do Alto Capivari, segue a jusante, recebendo tributários até a represa do Capivari, onde, para mover as turbinas da Usina Hidrelétrica Parigot de Souza, parte das águas é desviada para um túnel que atravessa a Serra do Mar, indo encontrar o rio Cachoeira, nas proximidades do Bairro Alto, já na bacia hidrográfica de Antonina, na planície costeira, com um desnível de 674 m (EMBRAPA \& IAPAR, 1984). A parte não transposta constitui um afluente do rio Pardo, que, por sua vez, deságua no rio Ribeira, com destino até o Complexo Estuarino Lagunar de Cananéia-Iguape.

A vegetação natural, original da área, de acordo com Veloso (1991), corresponde ao domínio da Floresta Ombrófila Mista (FOM), ou Floresta com Araucária, a qual é exclusiva do Planalto Meridional Brasileiro. Klein e Hatschback (1962), em estudo de fitofisionomia, que abrange a área dessa bacia, baseados num levantamento florístico de 1952, concluíram que os remanescentes da Floresta Ombrófila Mista já eram raros e perturbados pela intervenção humana. Quanto à floresta ciliar, muitas vezes é inexistente, sendo comum presenciar-se as estradas margeando os rios sem a mínima proteção dessa vegetação.

Na bacia predominam pequenas unidades de agricultura familiar produtoras de hortaliças, milho, feijão e alguns poucos animais criados para consumo próprio. O reflorestamento de bracatinga (Mimosa 
scabrella) é comum, e a atividade mineradora se faz presente com a extração de calcário, que vem se expandindo nos últimos anos e constitui uma importante atividade econômica dos municípios que fazem parte da bacia (Colombo, Almirante Tamandaré, Bocaiúva do Sul e Rio Branco do Sul).

\section{Descrição do método desenvolvido}

Este trabalho se desenvolveu basicamente em duas etapas principais. A primeira se organizou em torno das possíveis alterações da temperatura da água e do ar, tomadas na seção de controle, na ETA (Estação de Tratamento de Água/SANEPAR) de São Dimas, comparando-se entre si os anos de 1986 e 1987 (período) e esse conjunto (denominado de “série 86/87”) aos anos (períodos) mais recentes de 1998, 1999 e 2000 (denominada "série de 98 a 2000").

A ETA de São Dimas iniciou suas atividades em 1986. Assim, foram reunidos os boletins mensais de avaliação de qualidade de água "in natura" de outubro de 1986 a novembro de 1987, excetuando o mês de março, e os boletins referentes aos anos de 98, 99 e 2000. Os boletins posteriores a novembro de 87 e o do mês de março do mesmo ano estão extraviados, não tendo sido localizados nem na ETA São Dimas nem nos arquivos da SANEPAR.

Os dados de temperatura da água e do ar que constam nos boletins foram tomados em torno de 15 vezes ao dia. Assim, obteve-se um valor mínimo diário, um valor máximo diário e também um valor médio, referente à média aritmética de todos os valores do dia.

A temperatura constitui fator relativamente fácil de ser obtido, revelando muito sobre o ambiente, necessitando apenas de um instrumento de fácil acesso, manejo e leitura, o termômetro. Entretanto, para uma avaliação criteriosa das alterações térmicas nos ecossistemas aquáticos ao longo de um período mais extenso, há necessidade de observações sistemáticas, uma vez que existe uma sazonalidade anual inerente, representada por meses mais frios (inverno) e mais quentes (verão), bem como oscilações diárias representadas pela noite e pelo dia.

Assim, considerando esse aspecto dinâmico da temperatura, foi desenvolvido o índice "amplitude térmica relativa" (AT), que consiste na razão entre as amplitudes térmicas diárias do ar e da água:

$$
A T=\frac{\left(T_{\max A R}-T_{\min A R}\right)+1}{\left(T_{\max \dot{A} G U A}-T_{\min \dot{A} G U A}\right)+1}
$$

Dessa forma, da temperatura máxima diária do ar foi subtraída a temperatura mínima diária do ar, sendo o valor resultante dividido pela diferença entre temperatura máxima diária da água e a temperatura mínima diária da água. Optou-se por somar um ao numerador e também ao denominador para evitar resultados fracionados.

Essa análise envolveu três avaliações, pois se trabalhou considerando todos os meses do ano, somente os meses de inverno e somente os meses de verão. Para o inverno, foram considerados os meses de maio a setembro. Para os meses de verão foram considerados os meses de novembro a fevereiro. $\mathrm{O}$ mês de março não foi considerado devido à falta de dados desse mês para 1987, conforme exposto anteriormente.

Nesse índice, quanto maior o valor da razão, maior o tamponamento do sistema, ou seja, mais vagarosa é a resposta de variação térmica da água frente à variação térmica do ar. Assim, quando o resultado for maior que um, a temperatura da água pouco oscila com a alteração da temperatura do ar, podendo evidenciar uma maior cobertura de floresta ciliar. Quando for igual ou próximo de um, a temperatura da água reflete a temperatura do ar e, portanto a água não deve apresentar grande proteção no que se refere às florestas ciliares.

De posse desses valores diários, foram efetuadas análises estatísticas para verificar possíveis diferenças entre as séries consideradas.

\section{Análise estatística da amplitude térmica}

Uma análise de variância (ANOVA) foi aplicada aos dados do índice AT, obtidos pela equação (1). O resultado mostrou que as séries de 1986/1987 e 1998/1999/2000 possuem médias estatisticamente 
diferentes no nível de significância de $95 \%$, o que justifica uma análise ambiental mais detalhada das florestas ciliares, por meio de imagens, para as duas épocas distintas, que é feita a seguir.

\section{Floresta ciliar}

Para observação da floresta ciliar, foram utilizadas fotos aéreas pancromáticas de 1980 (Projeto Paraná; Quadrícula SG 22-X-D-I; escala aproximada 1:25.000/AEROSUL; faixas utilizadas: 51145 a 51148,54723 a 54730,51195 a 51198,51125 a 51132) e de 1996 (1 $1^{\text {a }}$ DL; escala 1:60.000; faixas utilizadas: $04-168,169,170,171 ; 03-117,118,119,120$; abril de 1996, em formato digital). Essas fotos foram escolhidas tanto pela disponibilidade quanto pela proximidade das séries 1986/1987 e 1998 a 2000 .

Para 1980, a floresta ciliar foi composta sobre a carta da rede de drenagem da bacia do rio Capivari, anteriormente demarcada em escala 1:20.000, observando-se fotos aéreas de 1980, em escala 1:25.000, sob auxílio de estereoscopia. Somente foram mapeadas as margens florestadas com extensão maiores de $20 \mathrm{~m}$ (aproximadamente $1 \mathrm{~mm}$ nas fotos aéreas), ao longo dos canais de drenagem e não somente ao lado dos rios.

Já para 1996, devido à pequena escala das fotos-aéreas (1:60.000), o método utilizado foi diferente, uma vez que seria impossível uma precisão de $20 \mathrm{~m}$ nessa escala. Assim, os mesmos canais de drenagem, já delimitados na carta de rede de drenagem, foram localizados nas fotos aéreas com o auxílio de estereoscopia e demarcados. Posteriormente, de posse dessas mesmas fotos em formato digital, ampliadas em grau máximo, de nitidez aproximada de 1:15.000, a rede de drenagem, previamente demarcada, foi localizada. Assim, orientando-se pelo uso do solo e feições da drenagem nas fotos, foram delimitados os trechos de floresta ciliar (de aproximadamente $20 \mathrm{~m}$ de largura) na carta de hidrografia e drenagem.

É necessário observar que a delimitação das formações florestais ciliares, extremamente trabalhosa, somente foi possível através de fotos aéreas, uma vez que o tratamento de imagens de satélite usuais no período em questão não poderia oferecer a precisão exigida neste trabalho.

Assim, a extensão de floresta ciliar foi dimensionada em quilômetros para as duas séries e em toda a bacia, e foram aplicados dois índices: densidade de floresta ciliar (DFC) e tamanho médio de fragmentos florestais ciliares. O índice de densidade de floresta ciliar (DFC) é definido da seguinte forma:

$$
D F C=\frac{C F C}{2 C D}
$$

Assim, dividiu-se o comprimento total de floresta ciliar (CFC), em quilômetros totalizados para ambas as margens, pelo comprimento total dos canais de drenagem (CD), também em quilômetros. $\mathrm{O}$ índice tem o dois no denominador, uma vez que cada trecho deveria estar protegido por florestas nos dois lados das margens.

Nesse índice, quanto maior o valor da razão, mais protegidos estarão os canais de drenagem, sendo 1 (um) o valor ideal. Nesse caso, todos os canais estariam cobertos por florestas ciliares.

Foram também obtidas as quantidades, em números, dos fragmentos de florestas ciliares e, além disso, foi elaborado e aplicado um índice denominado de "comprimento médio dos fragmentos florestais" (CMF). A expressão (3) define esse índice, que corresponde ao quociente entre a extensão (comprimento) de floresta ciliar (CFC), em quilômetros, e o número de fragmentos florestais (NFF) de floresta ciliar. Os dois índices foram obtidos para todas as sub-bacias. A explicação do desenvolvimento desses índices pode ser encontrada em Fritzsons (2003) e Fritzsons et al. (2004).

$$
C M F=\frac{C F C}{N F F}
$$

\section{RESULTADOS E DISCUSSÃO}

A título de caracterização, de posse dos dados diários de temperatura da água das séries estudadas, montou-se a tabela 1, onde estão presentes tanto a média das temperaturas médias da água e do ar como os maiores e os menores valores absolutos encontrados. 
A temperatura máxima mais elevada do ar no período amostrado ocorreu em março de 1986, e a da água, em junho de 2000, enquanto que a menor temperatura mínima do ar ocorreu em junho de 2000, e a da água, em julho de 2000. A título de comparação, em onze rios estudados por doze anos no estado do Paraná, a temperatura da água situou-se entre 25 e $15^{\circ} \mathrm{C}$ (Jica, 1995).

Tabela 1. Temperaturas máximas, mínimas e médias do ar e da água*.

Table 1. Maximum, minimum and medium air and water temperatures.

\begin{tabular}{lcc}
\hline \multicolumn{1}{c}{ Temperatura } & Ar $\left({ }^{\mathbf{0}} \mathbf{C}\right)$ & Água $\left({ }^{\mathbf{0}} \mathbf{C}\right)$ \\
\hline Média & 20 & 17,7 \\
Maior valor & 36 & 26 \\
Menor valor & -5 & 8 \\
Maior oscilação diária & 24 & 3,6 \\
Menor oscilação diária & 0 & 0 \\
\hline *: A média foi composta pelas médias de 3 anos $(98,99$ e 2000). As temperaturas absolutas foram obtidas da \\
amostragem de 86/87, 98,99 e 2000.
\end{tabular}

Em termos de amplitude térmica diária, a maior amplitude do ar ocorreu em julho de 2000 (24 $\left.{ }^{\circ} \mathrm{C}\right)$, e a da água, em setembro de $2000\left(3,6{ }^{\circ} \mathrm{C}\right)$, evidenciando que a temperatura da água se altera pouco diariamente, como já era de se esperar, devido à diferença de calor específico entre a água e o ar. O gráfico da figura 5 ilustra de maneira sintética esse aspecto.

Pode-se observar que, durante os períodos considerados para a construção do gráfico da figura 5, a amplitude térmica da água praticamente se manteve constante, embora a amplitude térmica do ar tenha sofrido considerável acréscimo nos anos mais recentes, sobretudo a partir de 1999. Esse fato não deve ser atribuído à maior inércia térmica da água, pois a análise dos dados diários mostra a grande sensibilidade das respostas térmicas da água desse rio em função das variações de temperatura do ar. Para rios mais caudalosos, com maior volume e vazão de água, deve-se esperar maior estabilidade térmica da temperatura da água e menor dependência das variações térmicas do ar atmosférico.

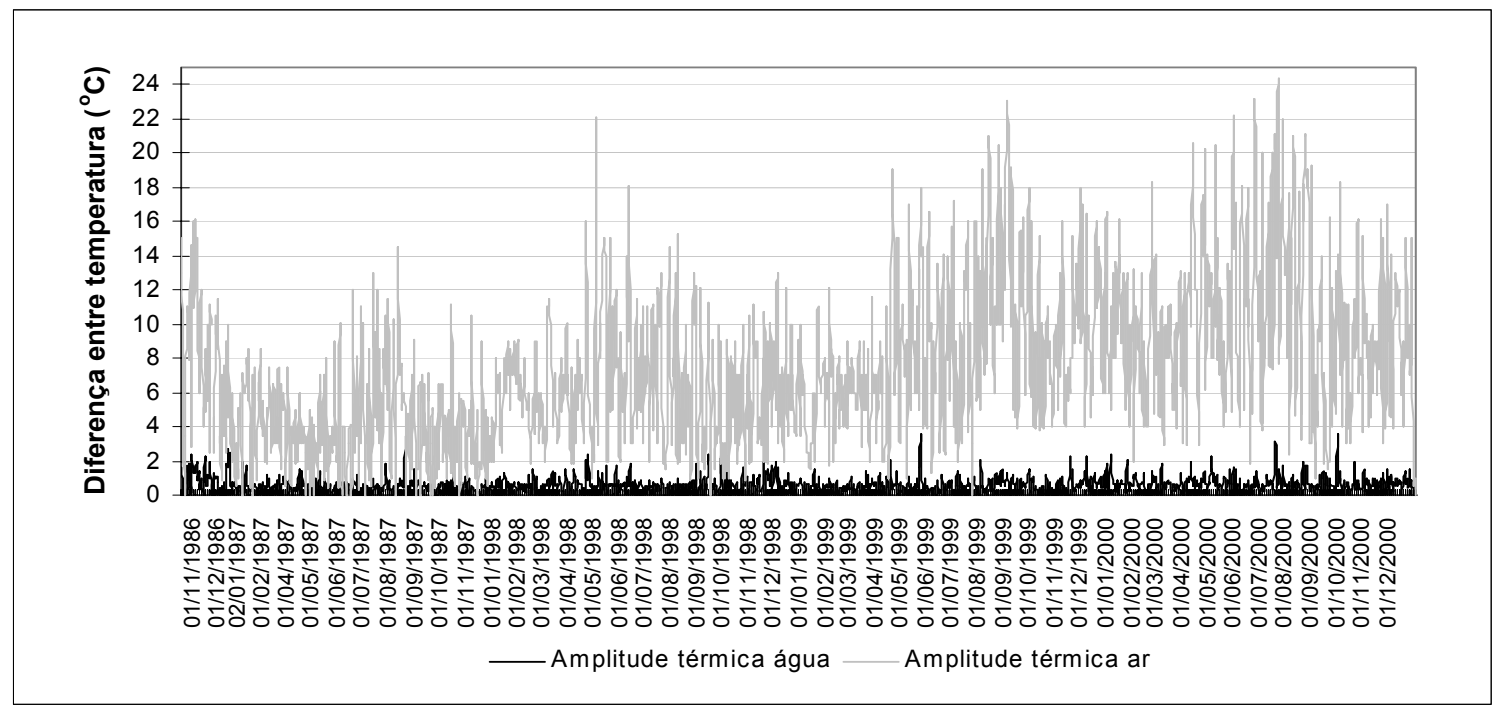

Figura 5. Variação térmica diária do ar e da água em 86/87, 98, 99 e 2000.

Figure 5. Water and air daily temperature range in 86/87, 98, 99 and 2000.

\section{Análise estatística da amplitude térmica}

A tabela 2 sintetiza o resultado da análise estatística descritiva para o índice "amplitude térmica ar/água" para todo o período, isto é, considerando o ano todo. 
Pode-se verificar que o valor médio do índice amplitude térmica ar/água da série 86/87 (período 1) é bem diferente dos demais e mais próximo do valor 1 , enquanto que o valor médio do período 2 , referente ao conjunto dos anos de 98 a 2000, é bem maior do que o do período 1 . Nota-se também que existe uma tendência a aumentar o valor do índice quando se consideram os anos de 98,99 e 2000 . O gráfico da figura 6 ilustra esse comportamento. Nesse gráfico, quando as barras não se sobrepõem, as médias dos anos são significativamente diferentes.

Tabela 2. Sumário estatístico da amplitude térmica ar/água para todo o ano.

Table 2. Summary statistics for air and water temperature range during the year.

\begin{tabular}{ccccccccccc}
\hline Coluna & Ano & $\begin{array}{c}\text { Dias } \\
\text { amostrados }\end{array}$ & Média & $\begin{array}{c}\text { Valor } \\
\text { máximo }\end{array}$ & $\begin{array}{c}\text { Valor } \\
\text { mínimo }\end{array}$ & Variância & $\begin{array}{c}\text { Desvio } \\
\text { Padrão }\end{array}$ & Soma & $\begin{array}{c}\text { Coef. de } \\
\text { Assimetria }\end{array}$ & $\begin{array}{c}\text { Coef. de } \\
\text { Curtose }\end{array}$ \\
\hline Período1 & $86 / 87$ & 373 & 2,97 & 11,1 & 0,4 & 2,90 & 1,70 & 1109,78 & 11,17 & 10,20 \\
Período2 & Atual* $^{*}$ & 109,5 & 4,84 & 19,0 & 0,7 & 6,56 & 2,56 & 5304,62 & 19,15 \\
Período3 & 98 & 365 & 3,87 & 16,0 & 0,7 & 4,54 & 2,13 & 1412,75 & 13,42 & 20,72 \\
Período4 & 99 & 365 & 5,18 & 16,0 & 1,0 & 6,28 & 2,50 & 1892,62 & 8,965 & 6,07 \\
Período5 & 2000 & 365 & 5,48 & 19,0 & 0,8 & 7,44 & 2,72 & 1999,28 & 11,72 & 14,51 \\
\hline *Atual
\end{tabular}

*Atual se refere aos anos de 98 a 2000.

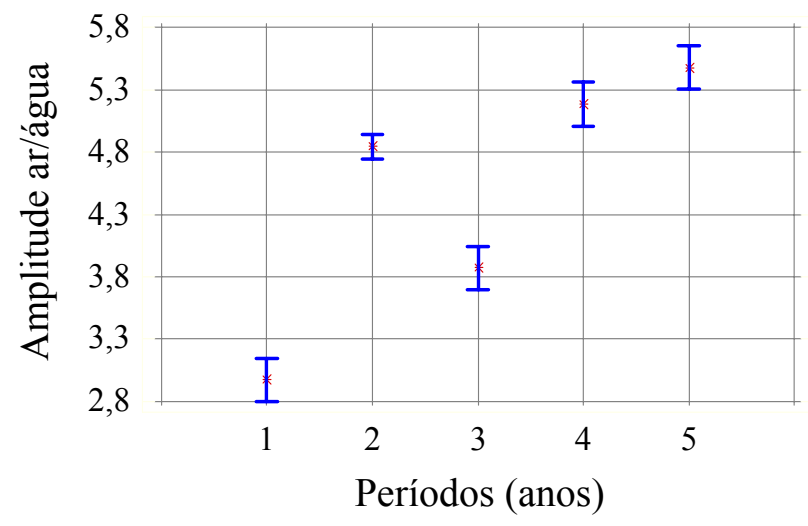

Figura 6. Gráfico de médias para o índice amplitude térmica ar/água todo o ano.

Figure 6. Media graphic for air and water daily thermic relative range index during the year.

Entretanto, observando-se a tabela 2, verifica-se que o padrão de assimetria e/ou de curtose está fora da amplitude entre -2 e +2 para os cinco períodos, o que indica que os dados não se ajustam ao modelo Gaussiano. Então, a falta dessa condição impossibilita a aplicação de um teste estatístico paramétrico. Assim, a análise da diferença entre os períodos foi feita por meio do teste não-paramétrico de Kruskal-Wallis, de forma que a hipótese nula testada foi a de igualdade entre as medianas, ao invés de médias. Desde que a probabilidade de as medianas serem as mesmas seja menor que 0,05 (valor p), infere-se que há uma diferença significativa entre as mesmas no nível de 95\% de confiança. Para determinar quais medianas são significativamente diferentes, pode-se observar o procedimento gráfico da figura 7 .

Nessa figura, enquanto a cruz dentro da caixa se refere à média, a linha vertical se refere à mediana. Quando os estreitamentos (flancos) se sobrepõem, isso significa que os períodos não diferem entre si dentro de um intervalo de 95\% de confiança. Assim, observa-se que o período 1 (1986/1987) apresenta a menor mediana de todos os períodos e é significativamente diferente do período 2 (1998 a 2000). A mesma análise foi feita para o período de inverno (figura 8) e para o de verão (figura 9). Para o inverno, deve-se observar que os períodos 4 e 5 se sobrepõem, não havendo diferença entre as medianas. 


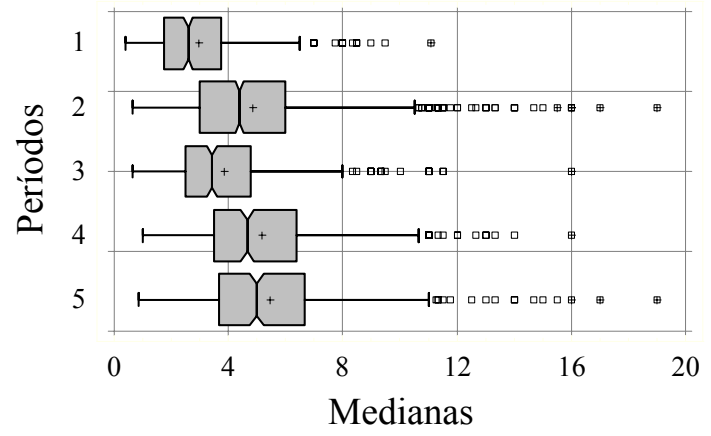

Figura 7. Gráfico de "caixa e bigodes" para amplitude térmica relativa todo o ano.

Figure 7. Box and Whisker plot for daily tHermic relative range index during the year.

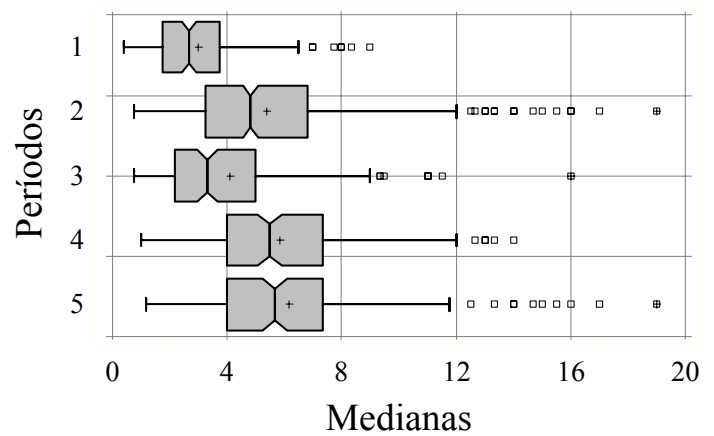

Figura 8. "Caixa e bigodes" para amplitude ar/água para os meses de inverno.

Figure 8. Box and Whisker plot for daily thermic relative range index during the winter.

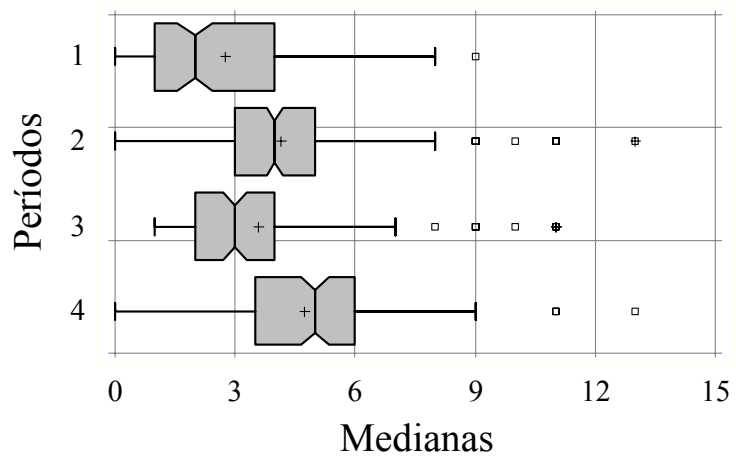

Figura 9. "Caixa e Bigodes" para amplitude térmica relativa para o verão.

Figure 9. Box and Whisker plot for daily thermic relative range index during the summer.

Nas figuras 7, 8 e 9 se observa a mesma tendência de aumento no valor do índice de amplitude térmica para os anos mais recentes. Isso evidencia um maior tamponamento do sistema e uma diferença significativa entre o primeiro período e o segundo período.

A tabela 3 sintetiza os valores encontrados, evidenciando o exposto acima. O gráfico da figura 10 ilustra a tabela 3 . 
Tabela 3. Valores médios dos índices de "amplitude térmica relativa" para as duas séries, para todo o ano, para o inverno e para o verão.

Table 3. Average values for daily thermic relative range index for two series, during the year, for winter and for summer.

\begin{tabular}{ccccccc}
\hline \multirow{2}{*}{ Índices } & \multicolumn{3}{c}{ Série de 86/87 } & \multicolumn{3}{c}{ Série de 1998 a 2000 } \\
\cline { 2 - 7 } & Média & V. Máximo & V. Mínimo & Média & V. Máximo & V. Mínimo \\
\hline Todo o ano & 2,97 & 4,07 & 0,4 & 4,84 & 19 & 0,66 \\
Inverno & 3,01 & 9,0 & 0,4 & 5,38 & 19 & 0,75 \\
Verão & 3,13 & 9,5 & 0,6 & 4,46 & 13 & 0,85 \\
\hline
\end{tabular}

Fonte: Tabela montada com os resultados da análise estatística.

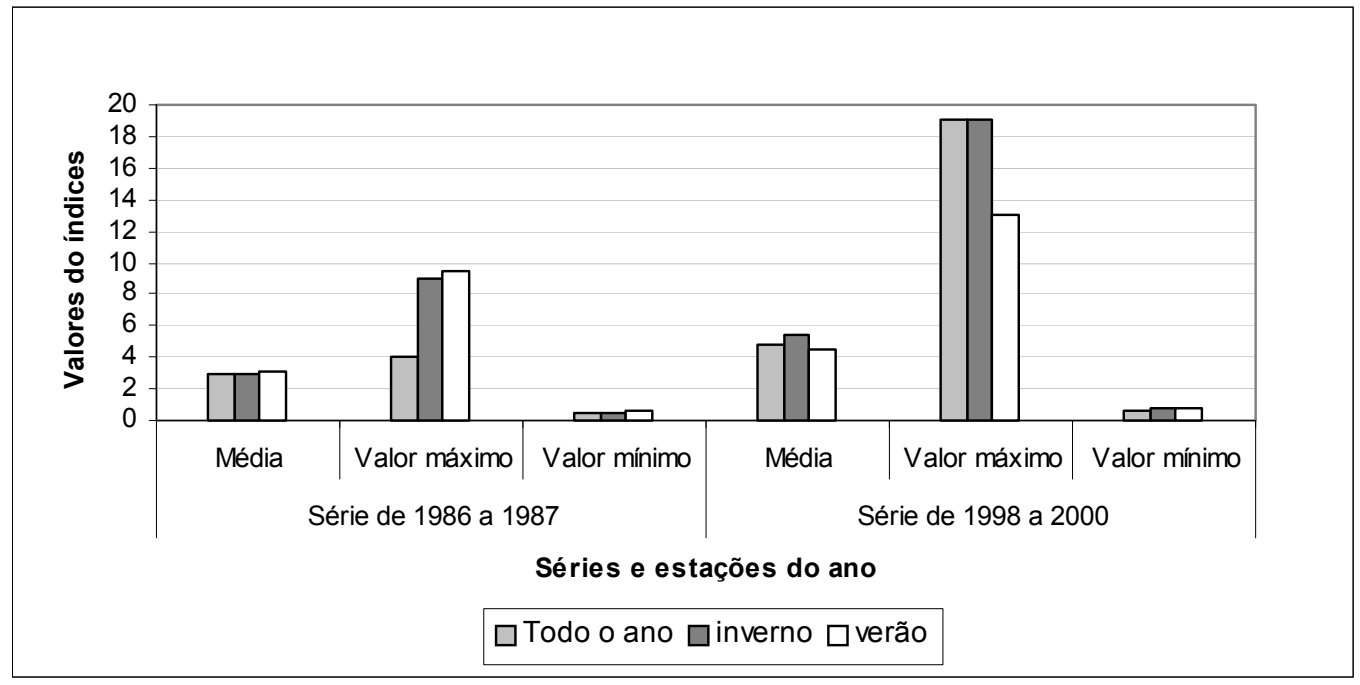

Figura 10. Valores médios do índice "amplitude térmica relativa" diária para as duas séries, para o ano todo, para o inverno e para o verão.

Figure 10. Medium values for daily thermic relative range index for two series, during the year, for winter and for summer.

Assim, avaliando-se os resultados apresentados pelos gráficos, nota-se que o valor do índice amplitude térmica relativa da série de 1986/1987 (período 1) foi menor, comparado ao da série de 1998 a 2000 e aos demais períodos analisados individualmente. Esse fato poderia ser decorrente de um maior tamponamento que ocorreu nos anos referentes às séries de 98 a 2000, o que poderia ser justificado pelo crescimento ou expansão das florestas ciliares no período médio de 12 anos que separa as duas séries. O estudo das fotos e imagens contribuiu para esclarecer essa questão.

A extensão das florestas ciliares foi quantificada para a bacia do Alto Capivari, em 1980, em 254,2 km. Em 1996, esse valor se elevou para 282,1 km, apresentando, portanto, uma alteração de mais de trinta quilômetros. Esse aumento foi tanto em termos de densidade florestal, ou seja, recobrimento de floresta ciliar nos canais de drenagem (em torno de 10\%), quanto no comprimento médio dos fragmentos florestais ciliares, que aumentaram em média 30\%, como demonstraram Fritzsons et al. (2004).

Observações sobre a expansão das florestas ciliares já foram efetuadas para a Região Metropolitana de Curitiba. Jacobs (2002) verificou uma expansão dessa tipologia florestal na bacia do Alto Iguaçu de $10,78 \%$, em 1984, para $17,18 \%$, em 1999 , ou seja, um aumento percentual de $6,4 \%$ em 15 anos.

Possivelmente, esses acréscimos observados se devem à ação de órgãos públicos, tais como o antigo ITC, o IAP e a EMATER, e mesmo da Polícia Florestal, pelo trabalho de fiscalização e conscientização dos proprietários rurais quanto à necessidade de preservação dessa tipologia florestal. Entrevistas realizadas com alguns moradores ribeirinhos reforçaram essa hipótese. 
Assim, provavelmente um valor mais elevado do índice "amplitude térmica", ocorrido nas águas do rio Capivari nos anos de 98 a 2000 em relação a 86/87, poderia ser atribuído à expansão das florestas ciliares. Com exceção do exutório da bacia, onde o rio atinge aproximadamente $8 \mathrm{~m}$ de largura em pequeno trecho, os rios são pequenos (de 2 a 3 metros de largura) e, assim, o sombreamento causado pelas florestas ciliares ao longo dos rios os protege tanto do aquecimento proveniente da radiação diurna quanto da perda de calor pela irradiação noturna.

\section{CONCLUSÕES E RECOMENDAÇÕES}

Este trabalho apresentou uma forma de avaliar a alteração da temperatura das águas do rio Capivari frente à alteração da temperatura do ar, por meio do desenvolvimento e aplicação do índice "amplitude térmica", numa abordagem temporal, considerando um intervalo médio de doze anos. Foi também observado um acréscimo das florestas ciliares quando se consideram os anos de 1990 em relação aos de 1980. Além de uma proteção do solo e das águas dos rios, esse aumento pode ter ocasionado um maior tamponamento térmico dessas águas, que se apresentaram com menores oscilações térmicas em 1998 a 2000 em comparação aos anos de 1986/87.

A análise estatística aplicada à análise do "índice da amplitude térmica", efetuada na primeira etapa do trabalho, forneceu motivos para o desenvolvimento do mapeamento e conseqüente quantificação das florestas ciliares.

Durante a análise estatística, tornou-se clara a necessidade de se trabalhar com as medianas relativas aos dados numéricos, e não com as médias. Isso decorre da alta dispersão dos dados, inerente à variabilidade natural quanto à opção de se trabalhar diretamente com dados diários e não com dados médios de períodos maiores, tais como de uma semana, um mês, etc.

Essa opção, em sentido inverso ao da maioria dos estudos versando sobre séries históricas de dados hídricos, deve-se ao fato de se perceberem as flutuações diárias dos dados não como meras variações ocasionais, em parte aleatórias e em outra, motivadas por eventuais erros de mensuração. A análise de variância do programa Statigraphics mostrou sua utilidade ao identificar parâmetros que se alteraram entre duas séries consideradas e entre períodos.

A elaboração e aplicação de índices, tais como o da "amplitude térmica" e os referentes às florestas ciliares, foram bastante úteis. $\mathrm{O}$ primeiro possibilitou a obtenção de respostas quanto à oscilação térmica das águas, e os demais facilitaram comparações mais detalhadas, no âmbito da análise temporal das cartas de uso e ocupação das terras.

Os boletins mensais de avaliação da qualidade de água da SANEPAR representam uma boa base de dados e podem ser muito úteis para pesquisas, embora, para trabalhos com maior nível de detalhamento químico e biológico, eles sejam insuficientes. A sua riqueza reside na quantidade e freqüência dos dados levantados, lembrando que cada dado de temperatura é composto de uma média de, no mínimo, 15 observações diárias, correspondentes ao número de horas em que a ETA está trabalhando no dia, ou seja, captando água fluvial e produzindo água tratada.

O monitoramento da temperatura das águas fluviais, das nascentes até o exutório da bacia, concomitantemente ao mapeamento das florestas ciliares, poderia esclarecer melhor a importância dessa tipologia vegetal na temperatura fluvial.

\section{REFERÊNCIAS}

ALLAN, D. Stream Ecology: structure and function of running waters. London: Chapman \& Hall, 1995.

ARCOVA, F. C; CICCO, V. de. Pesquisas em microbacias hidrográficas no laboratório de hidrologia florestal Walter Emmerick, Cunha, SP. II-Qualidade de água e Geoquímica. In: FÓRUM GEO-BIOHIDROLOGIA, 1., 1998, Curitiba. Anais... Curitiba: UFPR. 1998. p. 201-210.

BRANCO, S. M.; ROCHA, A. Poluição, proteção e usos múltiplos de represas. São Paulo: Edgard Blücher/CETESB, 1977.

EMBRAPA; IAPAR. Levantamento de reconhecimento dos solos do Estado do Paraná. Curitiba, 1984. t. 1. 
FRITZSONS, E. Avaliação temporal da qualidade de água como diagnóstico do uso e ocupação das terras na bacia do Alto Capivari, região cárstica curitibana - PR. Curitiba, 2003. 190f. Tese (Doutorado em Engenharia Florestal) - Setor de Ciências Agrárias, Universidade Federal do Paraná.

FRITZSONS, E.; MANTOVANI, L. E.; RIZZI, N. E. Aplicação de índices de paisagem às florestas ciliares na bacia do Alto Capivari - Região Cárstica Curitibana. Floresta, Curitiba, v. 34, n. 1, p. 3-11, 2004.

JACOBS, A. G. Dinâmica de uso e ocupação dos mananciais na região metropolitana de CuritibaPR. Curitiba, 2002. 259f. Tese (doutorado em Engenharia Florestal) - Setor de Ciências Agrárias, Universidade Federal do Paraná.

JAPAN INTERNATIONAL COOPERATION AGENCY. The master plan study on the utilization of water resources in Paraná state in the Federative Republic of Brazil. Tokyo, 1995. v. J.

KLEIN, R.; HATSCHBACK, G. Fitofisionomia e notas sobre a vegetação para acompanhar a planta fitogeográfica de parte dos Municípios de Rio Branco do Sul, Bocaiúva do Sul, Almirante Tamandaré e Colombo (Pr). Boletim da UFPR, Curitiba, n. 3, 93 p., 1962.

LIMA, W. de P. Função hidrológica da mata ciliar. In: SIMPÓSIO SOBRE MATA CILIAR. 1989, Campinas. Anais...Campinas: Fundação Cargill, 1989. p. 25-42.

MAACK, R. Geografia física do Estado do Paraná. 2. ed. Rio de Janeiro: J. Olympio, 1981.

MALANSON, G. Riparian landscapes. New York: Cambridge University Press, 1993.

MANTOVANI, L. E. Conseqüências ambientais e climáticas do desenvolvimento da região sudeste. In: INTERNATONAL SYMPOSIUM ON FOREST ECOSSYSTEMS - FOREST 96, 4., 1996, Belo Horizonte. Anais... Belo Horizonte: [s.n.], 1996.

NAGASAKA, A.; NAKAMURA, F. The influences of land-use changes on hydrology and riparian environment in a northern Japanese landscape. Landscape Ecology, Dordrecht, v. 14, p. 543-556. 1999.

NAKAMURA, F.; DOKAI, T. Estimation of the effect of riparian Forest on stream temperature based on heat budget. Journal of Japanese Forestry Society. v. 71. p. 387-394. 1989.

ODUM, E. P. Ecologia. Rio de Janeiro: Guanabara, 1983.

SUDERHSA Qualidade das águas interiores do Estado do Paraná - 1987-1995. Curitiba, 1997.

SUDERHSA. Dados de vazão mensal máxima, mínima e média da Chácara da Luz. 2000. Mensagem recebida por<elenfrt@brturbo.com.br>em 23 jan. 2001.

MOTA, S. Preservação e conservação de recursos hídricos. Rio de Janeiro: ABES. 1995.

UNESCO. Methods for water balance computations. Paris, 1974. 170p.

VELOSO, H. P. Classificação da vegetação brasileira adaptada a um sistema universal. Rio de Janeiro: IBGE. 1991. 